\title{
Creep Rupture Behavior in Dissimilar Weldment between FB2 and 30Cr1Mo1V Heat-Resistant Steel
}

\author{
Jiankun Xiong $\mathbb{D},{ }^{1,2,3}$ Jianping Yang $\mathbb{D}^{2,3}$ Haiyan Zhao $\mathbb{D}^{1}{ }^{1}$ Lin Yang $\mathbb{D},{ }^{2,3}$ Yang Guo $\mathbb{D},{ }^{3}$ \\ Fuheng Nie $\mathbb{D},{ }^{2,3}$ Dexing Xu $\mathbb{D},{ }^{2,3}$ Liping Yu $\mathbb{D},{ }^{4}$ and Fenghong Cao $\mathbb{D}^{5}$ \\ ${ }^{1}$ School of Mechanical Engineering, Tsinghua University, Beijing 100084, China \\ ${ }^{2}$ State Key Laboratory of Long-Life High Temperature Materials, Dongfang Turbine Co., Ltd, Deyang 618000, China \\ ${ }^{3}$ Manufacturing Technology Department, Dongfang Turbine Co., Ltd, Deyang 618000, China \\ ${ }^{4}$ School of Mechanical Engineering, Chengdu University, Chengdu 610106, China \\ ${ }^{5}$ Institute of Light Alloy Materials, Leshan Normal University, Leshan 614000, China \\ Correspondence should be addressed to Haiyan Zhao; 1029784558@qq.com and Fenghong Cao; lshcaofh2004@sina.com
}

Received 25 October 2021; Accepted 20 November 2021; Published 14 December 2021

Academic Editor: Weijie Yang

Copyright (C) 2021 Jiankun Xiong et al. This is an open access article distributed under the Creative Commons Attribution License, which permits unrestricted use, distribution, and reproduction in any medium, provided the original work is properly cited.

Creep rupture behavior of dissimilar weldments between FB2 and 30Cr1Mo1V heat-resistant steel by multipass welding at $783 \mathrm{~K}$ $\left(510^{\circ} \mathrm{C}\right)$ under different stresses $(260$ to $420 \mathrm{MPa})$ was researched. The fitted creep rupture exponent is 14.53 , and the $10,000 \mathrm{~h}$ extrapolating strength values predicted by the power law and Larson-Miller parameter show good agreement with experimental data. The samples exhibit a ductile fracture character and fracture in the weld fusion zone, which has a highly heterogeneous microstructure and grains with different morphologies and sizes and an obvious softening. There exist a decrease in the dislocation and precipitate density and an increase in the subgrain size in the weld metal after creep. The rupture is a transgranular fracture characterized by dimples as a result of microvoid coalescence. Laves phases along with copper-rich precipitates are observed in the vicinity of fracture surface, which creates a stress concentration that can cause transgranular fracture initiation.

\section{Introduction}

With the purpose of reducing carbon dioxide emissions which cause increasingly serious environmental pollution and meeting increasing demand on energy, research on renewable green energy is needed on the one hand; traditional ultrasupercritical (USC) generation technology with improved steam parameters like higher temperature and pressure has developed rapidly in recent decades on the other hand [1-3]. Dissimilar metal welding techniques have been gradually utilized to manufacture many important mechanical parts in industry, such as thermal power rotors in USC unit or large petrochemical pressure vessels like reactor and separator in petrochemical industry, since dissimilar welding applications have the advantages like unique property combinations, weight reductions, lower costs, and improved energy efficiency [4]. However, as known, it is challenging to produce excellent dissimilar welds due to different chemical and physical properties (melting point and coefficient of linear expansion, thermal conductivity, etc.) between different base metals $[5,6]$. Generally, the properties of dissimilar weld depend on the properties of the base materials, the selection of the welding methods and parameters, and the postweld heat treatment process; and the welds exhibit different mechanical property irregularities due to uneven changes in the microstructure [4].

A great amount of researches [6-13] have been implemented to assess the creep deformation and fracture behavior of dissimilar weld joints of creep-resistant steels. For instance, Dagmar [12] researched the precipitates quantitatively in weld joints of COST F and FB2 creep-resistant steels with conventional and accelerated creep tests, and the fracturing was located in HAZ of the F steel. Creep resistance of similar and dissimilar weld joints of P91 steel (a similar 
TABLE 1: Main chemical compositions of parent material.

\begin{tabular}{lcccccccccccc}
\hline Material & $\mathrm{C}$ & $\mathrm{Si}$ & $\mathrm{Mn}$ & $\mathrm{Cr}$ & $\mathrm{Mo}$ & $\mathrm{V}$ & $\mathrm{Ni}$ & $\mathrm{Cu}$ & $\mathrm{W}$ & $\mathrm{Co}$ & $\mathrm{B}$ & $\mathrm{Nb}$ \\
\hline FB2 & 0.11 & 0.099 & 0.38 & 9.14 & 1.53 & 0.18 & 0.14 & 0.022 & 0.01 & 1.37 & 0.0081 & 0.05 \\
30Cr1Mo1V & 0.27 & 0.073 & 0.71 & 1.11 & 1.26 & 0.23 & 0.53 & 0.023 & & & \\
\hline
\end{tabular}

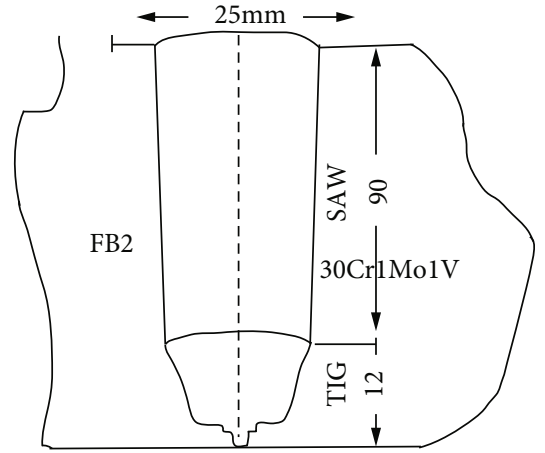

(a)

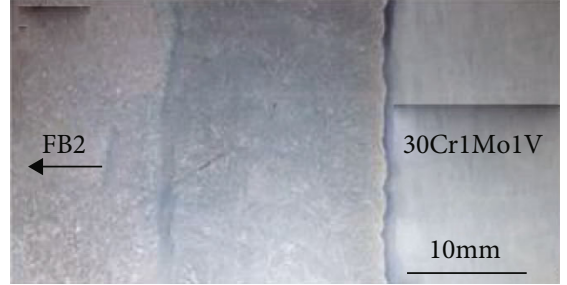

(b)

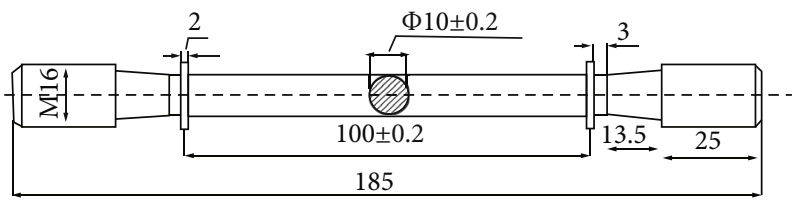

(c)

Figure 1: (a) Edge shape of welded joints, (b) macro cross-section structure of welded joints, and (c) schematic drawing of the creep specimen design.

weld joint of 9Cr1Mo steel and a dissimilar weld joint of 9Cr1Mo and 2.25Cr1Mo steels) was studied in Ref. [8] with two experimental weld joints, finding out that for high temperature, the similar weldment ruptured in the HAZ of the parent material while the dissimilar weldment's rupture position was in the heat-affected zone (HAZ) of the weld metal. Evaluation of the creep behavior of $2.25 \mathrm{Cr}-1 \mathrm{Mo} /$ 9Cr-1Mo dissimilar weld joint with its base and weld metals was performed by Ref. [10]. In this research, dissimilar weld joint of FB2 (13Cr9Mo1Co1NiVNbNB) and 30Cr1Mo1V heat-resistant steel was produced. Compared with other metals which may perform as functional material $[14,15]$, heat-resistant steels have been commonly used as structure material in ultrasupercritical (USC) power plants owing to their creep and oxidation resistance and great hightemperature strength. Ferritic (9-12 wt.\%) Cr steels [16] are recognized as the key materials for producing casings and forgings for turbines of USC units, and FB2 steels were developed under the European Cooperation in Science and Technology (COST) program [17] for large-scale forging production applying under creep temperature $620^{\circ} \mathrm{C}$. $30 \mathrm{Cr} 1 \mathrm{Mo1V}$ [18-23] is a type of turbine-rotor steel, which was designed in the 1990s to manufacture the highpressure or intermediate-pressure rotors in USC units, serving at a pressure between 23.5 and $25 \mathrm{MPa}$ and a temperature range of 538 and $540^{\circ} \mathrm{C}$. Though studies have been carried out to research long-term creep behavior of the heat-resistant steels and their weldments, the creep behavior of the dissimilar FB2 and 30Cr1Mo1V weldment still needs detailed research.

Herein, in this paper, dissimilar welded pipe with FB2 and $30 \mathrm{Cr} 1 \mathrm{Mo} 1 \mathrm{~V}$ forging pieces for the steam turbine rotor were manufactured in Dongfang Turbine Company in China, which satisfied all requirements set by technical standards. Creep testing at $783 \mathrm{~K}\left(510^{\circ} \mathrm{C}\right)$ under different stresses was carried out. Microhardness values were obtained along the crept welded joint. Optical microscopy (OM) and scanning electron microscopy (SEM) were applied to explore microstructure, fracture morphology, and precipitates in crept specimens. The main goal of this work is to investigate the creep stress sates under $783 \mathrm{~K}\left(510^{\circ} \mathrm{C}\right)$ on the creep rupture behavior of the dissimilar weld joint of FB2 and 30Cr1Mo1V.

\section{Materials and Methods}

The chemical compositions of the two base metals are displayed in Table 1. The heat treatment of forged FB2 consisted of one-time quenching and tempering twice, forming full lath martensite microstructure. The 30Cr1Mo1V forging first experienced a preheat treatment process including normalizing and the following tempering and then was quenched and tempered, to form bainite along with ferrite structure. The multilayer welding was carried out employing 


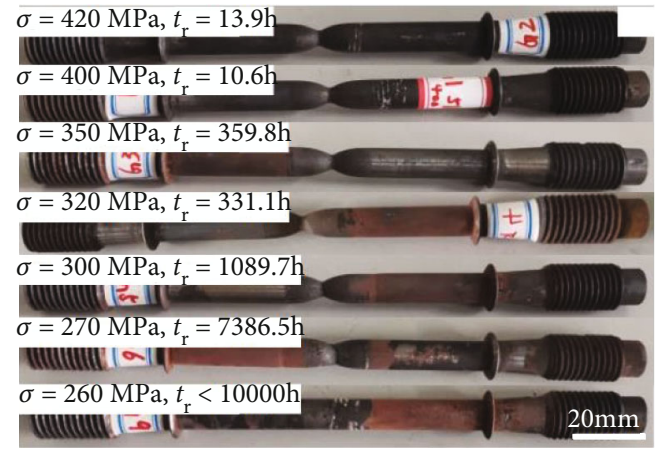

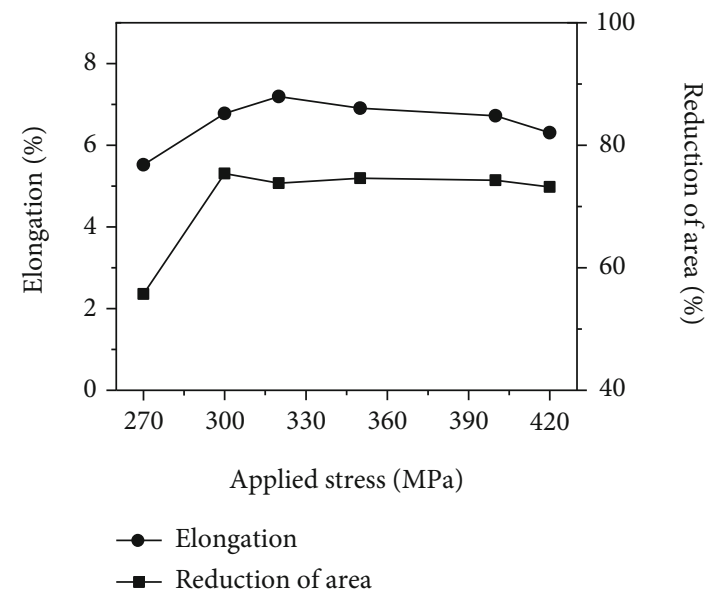

(b)

Figure 2: (a) Fractured specimens after creep test at $783 \mathrm{~K}\left(510^{\circ} \mathrm{C}\right)$ under different stresses and (b) creep ductility evolution with respect to stress.

tungsten inert gas arc welding (TIG-W) for backing weld and submerged arc welding (SA-W) for the subsequent multipass welding. Welding wire TG-S2CMH and US-521H were adopted for TIG and SA welding, respectively. After the welded circular pipe was produced, the postweld heat treatment (PWHT) was conducted to stabilize microstructure and relieve internal stress.

Round tensile creep specimens were machined parallel to the axial direction of the welded pipe with two types of parent materials, and the welded fusion zone occupied a center position, and the design and dimensions of the creep specimens are shown in Figure 1. The uniaxial tensile creep tests were carried out employing a leveraged creep machine (CRIMS RD2-3) in the atmosphere, with high-temperature furnace to keep a high temperature of $783 \mathrm{~K}\left(510^{\circ} \mathrm{C}\right)$, under seven applied stress levels, 420,400,350,320,300, 270, or $260 \mathrm{MPa}$. In order to monitor and regulate the test temperature, two NiCr-NiSi thermocouples were attached to the specimen. Gage length displacement and cumulative creep strain were measured with double linear variable displacement transducer (LVDT) extensometers, whose resolution was $0.001 \mathrm{~mm}$. The gage length and cross-sectional area of each specimen were measured before and after creep testing to calculate the percent elongation and the percent reduction in area. Microhardness values were obtained along the crept welded joint. Optical microscopy (OM) and scanning electron microscopy (SEM) equipped with energydispersive spectrometer (EDS) were applied to explore microstructure, fracture morphology, and precipitates in crept specimens.

\section{Results and Discussion}

3.1. Fractured Specimens. Photos of welded specimens between FB2 and $30 \mathrm{Cr} 1 \mathrm{Mo} 1 \mathrm{~V}$ after creep tests at $783 \mathrm{~K}$ under different stresses from 420 to $260 \mathrm{MPa}$ are displayed in Figure 2(a). All of the investigated samples fractured in the weld fusion zone. The location of fracture of dissimilar weldments depends not only on the parent material but also

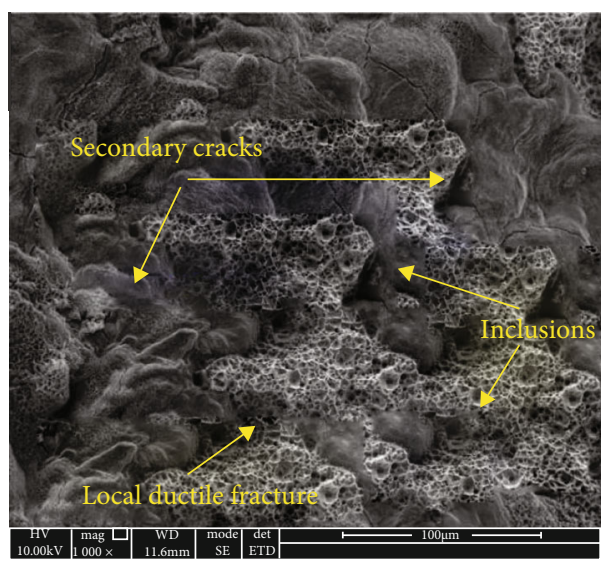

Figure 3: SEM fractograph which shows secondary cracks, inclusions, and local ductile fraction in the specimen after creep test at $783 \mathrm{~K}\left(510^{\circ} \mathrm{C}\right)$ under $320 \mathrm{MPa}$.

on the creep test conditions. For example, the fracture of the weldment of FB2 and COST F creep-resistant steels was in the heat-affected zone (HAZ) of the F steel in Ref. [12]. Moreover, according to Ref. [8] which studied the P91/P22 weld joint, the fracture was initiated in P22 parent material at relatively low temperatures and high stresses while fracture occurred in the weld metal at higher temperatures and lower stresses. Based on the research of Ref. [24] on dissimilar steel welded joints between ferritic steel and austenitic stainless steel (T92/HR3C), the rupture positions vary with change in stresses, from T92 base material to HAZ of T92 and to weld seam with decreasing stress. A certain amount of localized plastic deformation, i.e., the necking, after various creep damages can be observed in samples under stresses no less than $270 \mathrm{MPa}$, with the measured percentage elongation ranging from $5.52 \%$ to $7.19 \%$ and the percentage reduction of area from 55.73 to $73.19 \%$. The detailed percentage elongation and reduction of area values under various creep conditions are displayed in Figure 2(b). The 


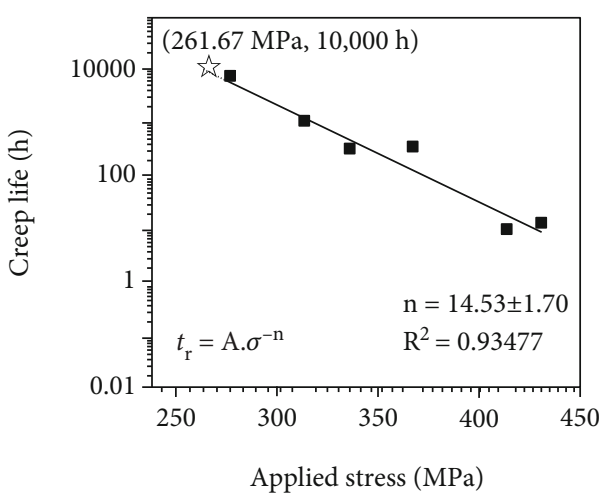

(a)

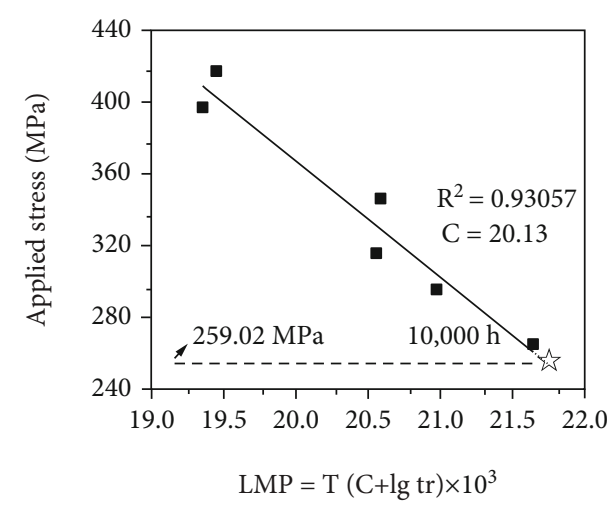

(b)

Figure 4: (a) Variations between creep life and applied stress and (b) relationship between creep rupture strength and LMP, at $783 \mathrm{~K}$ $\left(510^{\circ} \mathrm{C}\right)$.

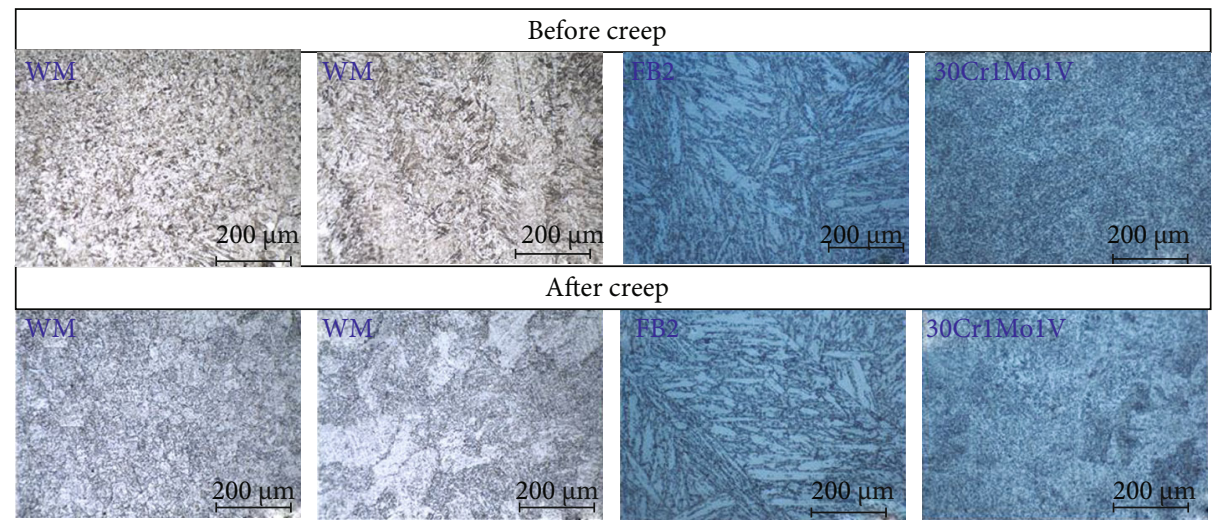

FIGURE 5: OM images showing microstructure at different zones of the dissimilar weldments before and after creep at $783 \mathrm{~K}\left(510^{\circ} \mathrm{C}\right)$ under $300 \mathrm{MPa}$ with a magnification of 50 .

creep ductility exhibits little change between 420 and $300 \mathrm{MPa}$, and it drops dramatically at $270 \mathrm{MPa}$. The rupture time exhibits an increasing trend with the drop of applied stress, and the welded specimen does not break till the target time of 10,000 hours for the lowest stress of $260 \mathrm{MPa}$. Roomtemperature and high-temperature tensile testing has been implemented on welded joints, and just like creep testing, all specimens ruptured in the weld metal, and the strength decreases significantly while the ductility values increase slightly with testing temperature. Under room temperature, the yield strength, tensile strength, elongation, and reduction of the area are $692 \mathrm{MPa}, 617 \mathrm{MPa}, 13 \%$, and $72 \%$, and they change to $463 \mathrm{MPa}, 430 \mathrm{MPa}, 14 \%$, and $78 \%$ for $823 \mathrm{~K}$ $\left(550^{\circ} \mathrm{C}\right)$, respectively.

It is worth noting that the specimens under 400 and $320 \mathrm{MPa}$ deviate from the above rupture time increasing with the drop of the stress trend, which is probably as a result of the welding defects. Figure 3 displays the SEM fractograph of the specimen at $320 \mathrm{MPa}$, and secondary cracks and inclusions can be observed. Besides, small local ductile fracture regions which show dimpled fracture surfaces spread out across the fracture surface, implying that the fraction in this specimen is not pure ductile fraction.
3.2. Creep Rupture Exponent and Life Assessment. Variations between applied stress $(\sigma)$ and creep rupture life $\left(t_{\mathrm{r}}\right)$ of the welded joint are logarithmically plotted in Figure 4 according to the equation $t_{\mathrm{r}}=A \bullet \sigma^{-n}$, where $A$ is a coefficient and $n$ is creep rupture exponent. The fitted creep rupture exponent is 14.53 , with a coefficient of determination, $R^{2}$, of 0.93477. Zhang et al. [25] have successfully utilized this law to predict the creep life of weldments between an austenite heat-resistant steel and a nickel base weld metal at a specified temperature. The extrapolating strength of rupture time at $10,000 \mathrm{~h}$ at $783 \mathrm{~K}\left(510^{\circ} \mathrm{C}\right)$ can be obtained as $261.67 \mathrm{MPa}$, which agrees with our experimental data (see Figure 2). In order to evaluate the combined influence of the exposed temperature and applied stress on the creep rupture of the weldment, the Larson-Miller parameter (LMP) with a form of $P=T\left(C+\lg t_{r}\right)$ where $C$ is the material constant, which is one of the three versions of time-temperature parametric (TTP) methods with a relative rate of success [26], is utilized to analyze the creep data. The calculated results are displayed in Figure 4. The extrapolating strength of rupture time at $783 \mathrm{~K}$ for $10,000 \mathrm{~h}$ is $259.02 \mathrm{MPa}$, with a LMP value of approximately $2.16 \times 10^{4}$. Therefore, the $10,000 \mathrm{~h}$ extrapolating strength values predicted by the power law and LMP methods show good agreement. 


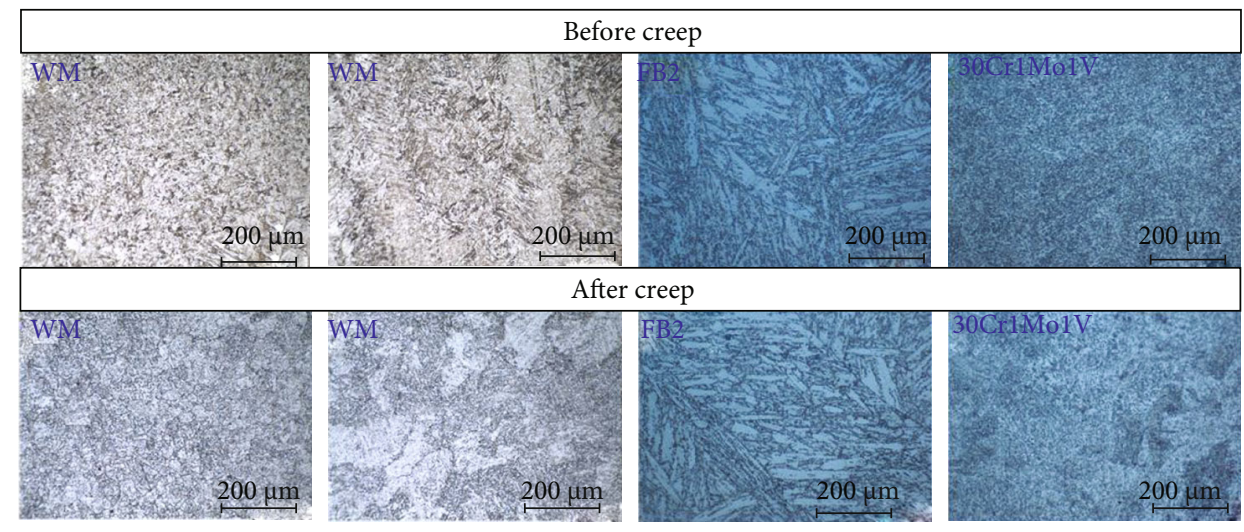

FiguRE 6: OM images showing microstructure with a magnification of 100 for weld fusion zone and with a magnification of 1000 for the parent materials of the dissimilar weldments before and after creep at $783 \mathrm{~K}\left(510^{\circ} \mathrm{C}\right)$ under $300 \mathrm{MPa}$.

3.3. Microstructure. A microstructure inhomogeneity of different microzones of the welded joints before and after creep can be clearly observed in Figures 5 and 6, before and after creep testing. The OM image of parent material FB2 shows a typical microstructure of high $\mathrm{Cr}(9-12 \mathrm{wt} . \% \mathrm{Cr})$ ferritic steel; that is, prior austenite grains are divided into packets and further into blocks, and many elongated subgrains which contain a high density of free density can be observed in the blocks [27]. As for the $30 \mathrm{Cr} 1 \mathrm{Mo1V}$, it has a much smaller prior austenite grains compared to FB2, and a bainite and ferrite structure can be observed, agreeing with previous studies [21-23]. The heat-affected zone exhibits different microstructures including coarse-grain zone and fine-grain zone, whose evolution is mainly influenced by weld thermal cycle (the heating and cooling rate), peak temperature experienced, dwelling time, number of welding passes, and postweld heat treatment.

As displayed in Figure 2, the fracture site is located at the weld fusion zone, and accordingly, the weld seam (Figure 6) shows a complex microstructure of bainite, martensite, and coarse primary ferrite. Various crystallizing morphologies including fine equiaxed grains and coarse columnar crystals and dendrites can be observed in Figure 1(b) even with the unaided eyes. Such microstructure variation can be attributed to the effect of each pass on previous welding pass. The temperature gradient between weld and base metal leads to rapid solidification that results in the formation of columnar austenite grains. For multipass welding, the subsequent passes might cause autotempering of previously deposited metal, leading into the formation of fine former austenite grain structures in previously near deposited metal. It can be found in the weld seam of ruptured dissimilar weldment at $783 \mathrm{~K}\left(510^{\circ} \mathrm{C}\right)$ under $300 \mathrm{MPa}$ (Figure 6) that the equiaxed grain zone is increased while the columnar crystals and dendrites are decreased, perhaps because previously formed martensitic structure in the weld seam is not stable and has a tendency to degenerate into ferritic equiaxed crystals with low density of dislocation as a result of recovery and recrystallization during high-temperature creep.

3.4. Creep Resistance Analysis in Weld Metal. Weldments have a highly heterogeneous microstructure; thus, the

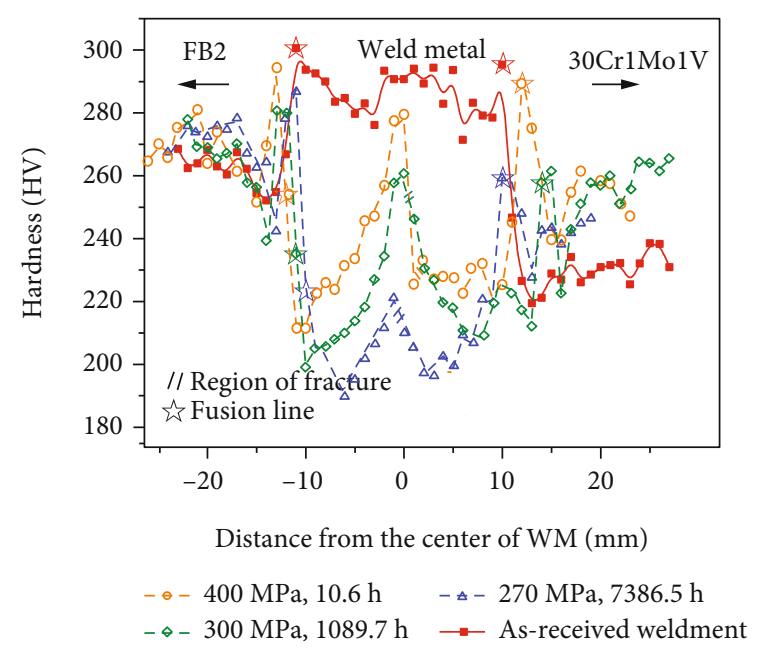

FIgURE 7: Hardness profile across the specimen before and after creep ruptured at $783 \mathrm{~K}\left(510^{\circ} \mathrm{C}\right)$ under 400,300 , or $270 \mathrm{MPa}$.

microhardness can vary considerably over relatively short distance. Figure 7 displays the hardness profile across the original weldment before creep testing and the specimens after testing at $783 \mathrm{~K}$ at an applied stress of 400,300 , or $270 \mathrm{MPa}$. Please note that the width of the weld fusion zone for crept specimens in the figure is smaller than its real dimension, because a section of the fractured specimen, approximately $10 \mathrm{~mm}$, was cut off to observe the fracture surface. The practical widths of the weld metal for the crept specimen should be greater than those of the original weld joint, as a result of the plastic deformation in creep testing. It can be seen clearly that the base metal of FB2 exhibits greater microhardness values than $30 \mathrm{Cr} 1 \mathrm{Mo} 1 \mathrm{~V}$, whether before creep tests or after. The hardness in weld metal exhibits a decline trend with decreasing stress and increasing creep time while the hardness in other microzones of the weldment does not show such a sharp decline. Therefore, the weld fusion zone changes from the maximum hardness region to the minimum during creep testing, which is more obvious for the regions on the side near the fusion boundary, indicating that a softening phenomenon occurs in weld metal. This result is different from the results from previous 


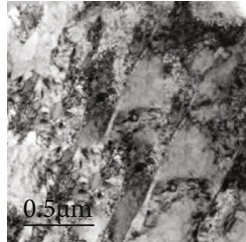

(a)

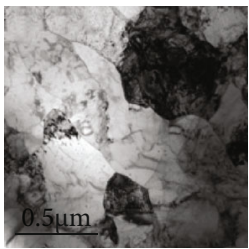

(c)

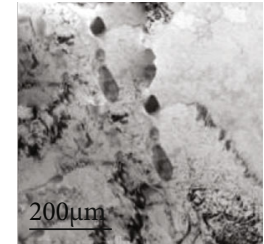

(b)

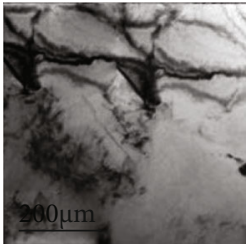

(d)

Figure 8: Bright field TEM micrographs of $(a, b)$ martensitic lath structure in weld metal which does not experience stress and (c, d) microstructure of the weld metal near the rupture site showing polygonized structure after 7386.5-hour creep.
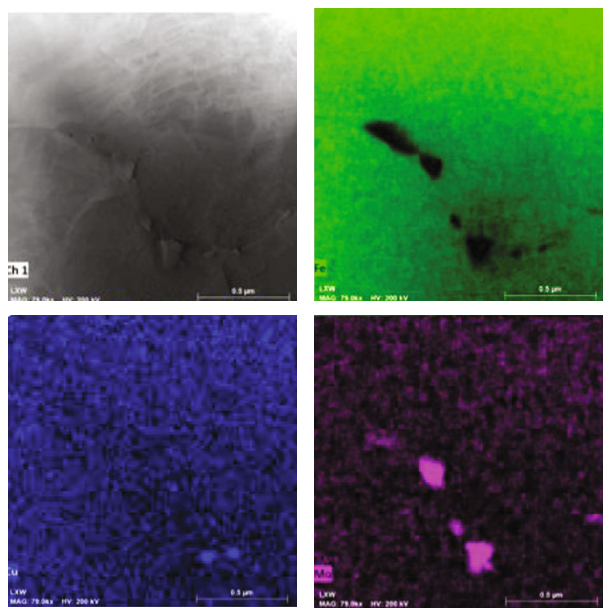
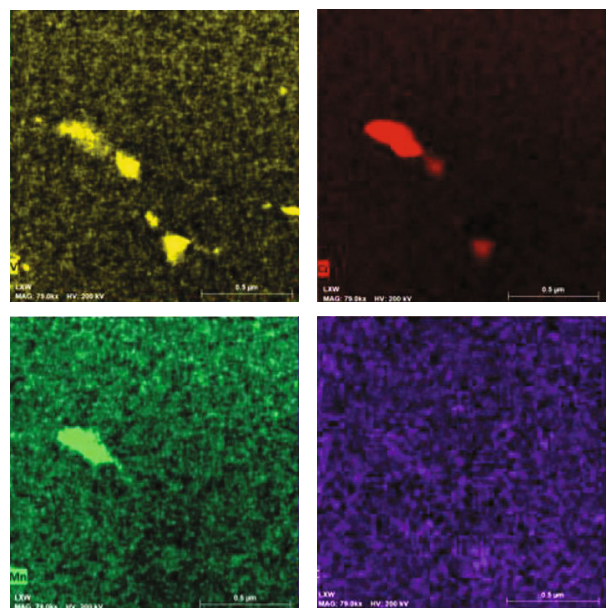

FIGURE 9: EDS map scan of precipitates in the weld metal of specimen crept after 7386.5 hours.

researches on other heat-resistant steel weldments [25, 28-30], where hardness of the FGHAZ/IC-HAZ is the lowest, and soft FGHAZ/IC-HAZ shows higher susceptibility to type IV cracking.

There are mainly three strengthening mechanisms: solution strengthening, precipitation strengthening, and dislocation substructure for high Cr ferritic steel [27]. It is known that martensitic and bainitic transformation in the weld seam can introduce an extremely high density of dislocation, and these dislocations decrease rapidly with respect to the microstructural change during creep testing, resulting in the decrease in creep strength and microhardness. The evolution of dislocation density in X20 and P91 (two martensite ferritic steels), during heat treatment and creep, was analyzed using transmission electron microscopy (TEM) and X-ray diffraction (XRD) in Ref. [31], and according to their results on $\mathrm{P} 91$, the dislocation density is $4.20 \times 10^{14} \mathrm{~m}^{-2}$ after quenching and drops to $0.60 \times 10^{14} \mathrm{~m}^{-2}$ after one hour tempering, to $0.06 \times 10^{14} \mathrm{~m}^{-2}$ in crept specimen. Figures 8 (a) and 8 (b) show the TEM micrographs of elongated martens- itic lath structure in weld metal which does not experience stress; there exists a high density of dislocations within the laths and subgrains, which is mainly attributed to the formation of martensite during welding and subsequent heat treatment. The microstructural studies of specimen crept at $270 \mathrm{MPa}$, as shown in Figures $8(\mathrm{c})$ and $8(\mathrm{~d})$, exhibit a decrease in the dislocation and precipitate density and an increase of the size of precipitates. Besides deterioration of the abovementioned strengthening mechanisms, Laves phase precipitation, $(\mathrm{Fe}, \mathrm{Cr})_{2}(\mathrm{~W}, \mathrm{Mo})$, weakens the creep strength by removing Mo from solid solution. Accordingly, Laves precipitates along with $\mathrm{Mn}$ - and $\mathrm{Cu}$-rich precipitates can be observed along grain boundaries based on Figure 9, which will be further discussed in the following section.

Moreover, previous studies demonstrated that the hardness is affected not only by the dislocation structure but also by other microstructures such as substructures like microvoids and precipitates [29]. Figure 10 displays the evolution of microvoids with respect to creep stress. It can be found out that a great amount of microvoids form in 

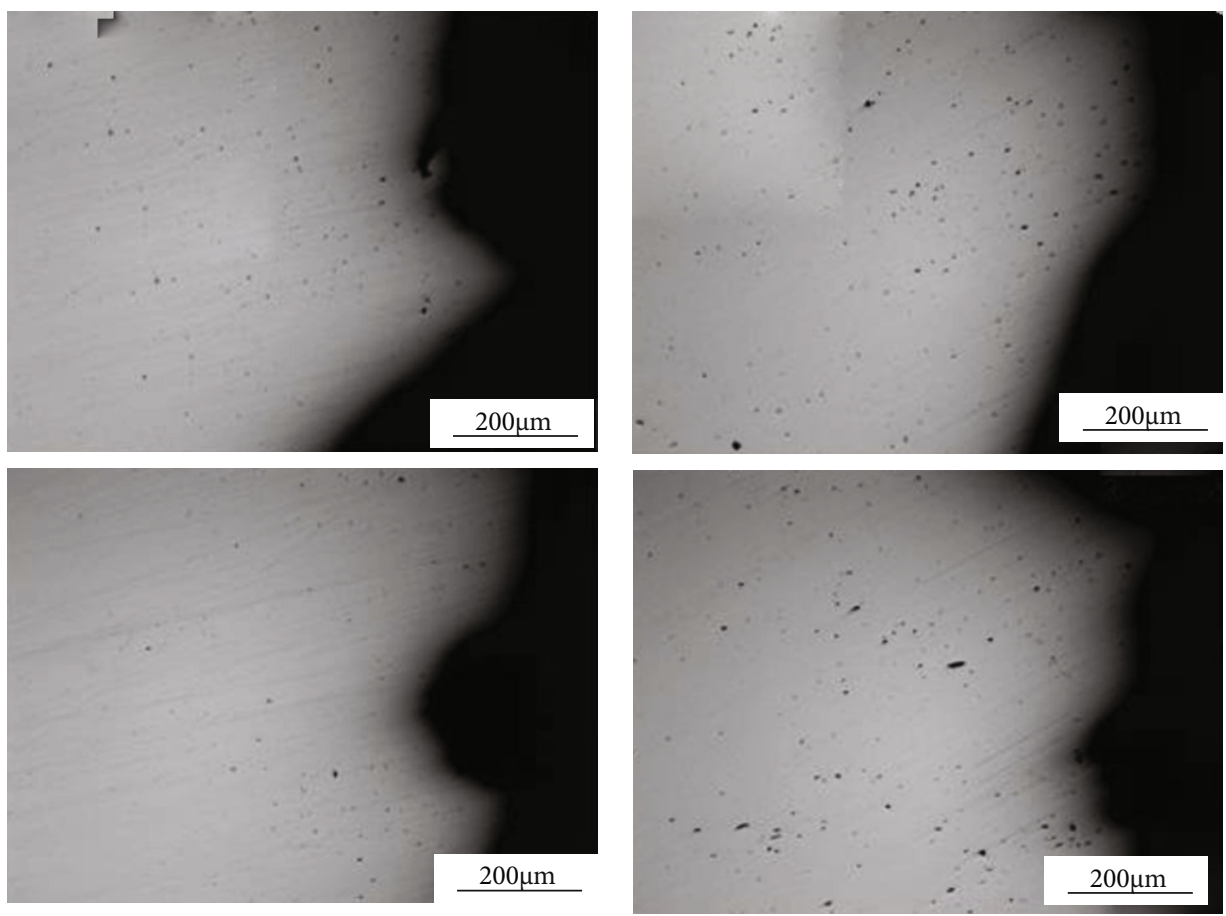

(a)

(b)
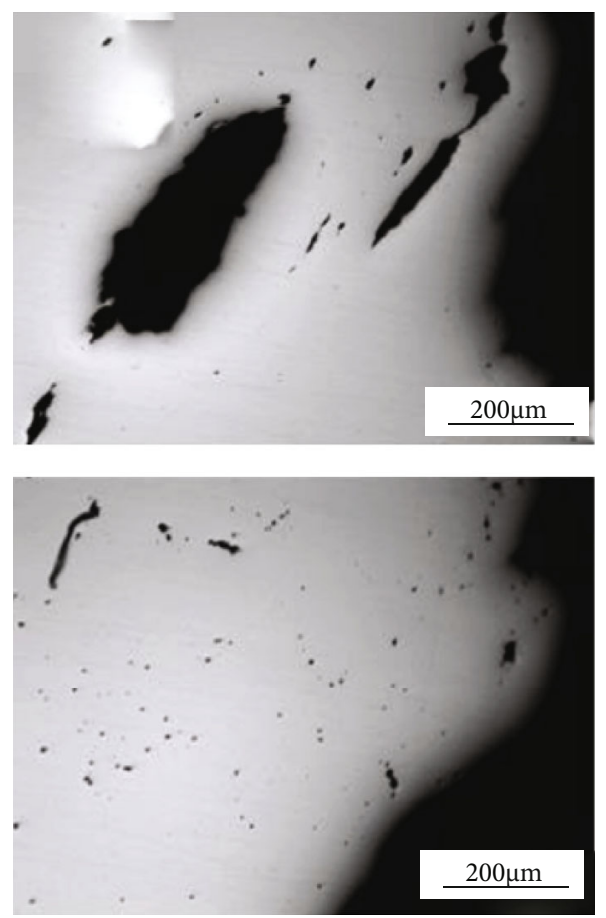

(c)

FIGURE 10: Microvoids near fracture in crept specimens under (a) 420, (b) 350, or (c) $270 \mathrm{MPa}$.

Figure 10(a), and the voids grow and eventually coalesce with the decrease of creep stress and the increase of creep time. More large-sized voids can be observed under $270 \mathrm{MPa}$, and the area fraction of voids has also been increased.

3.5. Fractography and Precipitate Analysis. Figure 11 displays creep microvoids and precipitates near the fracture surface.
As displayed above, all of the investigated samples exhibit necking after various creep damages, which is a ductile fracture character. A tearing region can be clearly observed on each fracture surface, which is considered an eventual plastic deformation (tearing) of the fracture procedure. The SEM morphologies at the smooth region of the ruptured specimens exhibit transgranular fracture features which are characterized by dimples as a result of microvoid coalescence 

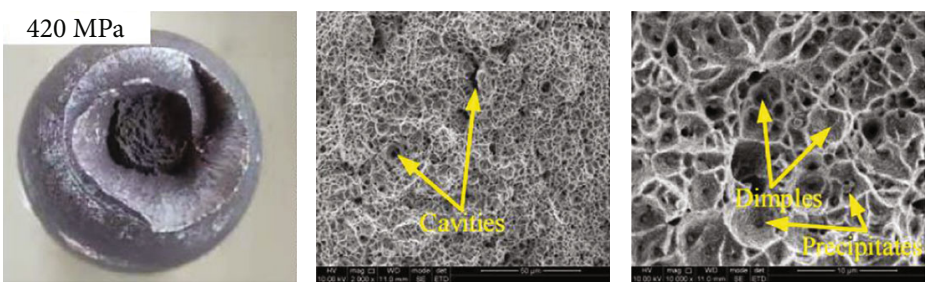

(a)
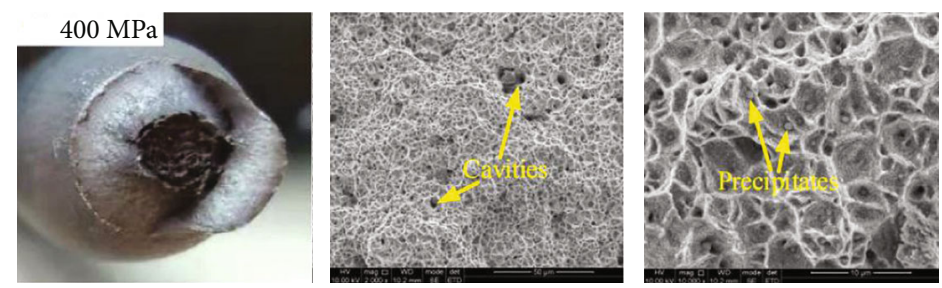

(b)
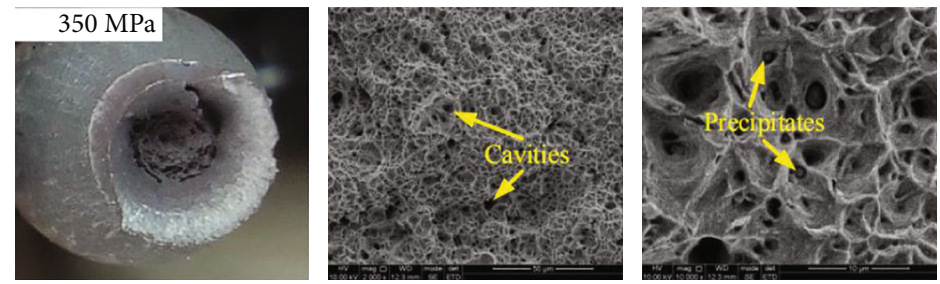

(c)
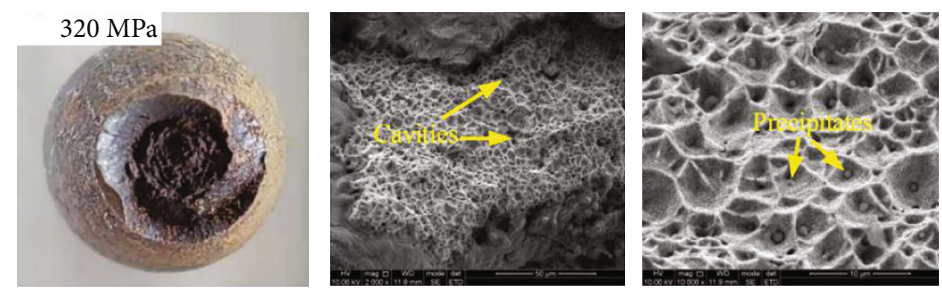

(d)
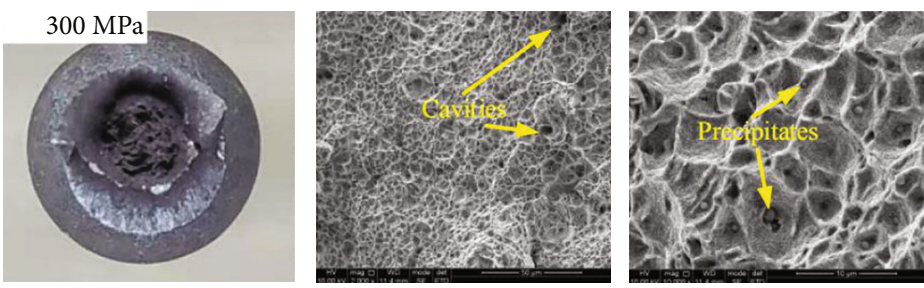

(e)
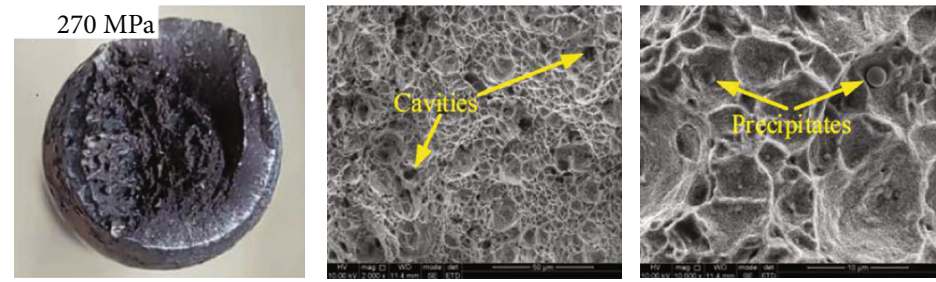

(f)

Figure 11: SEM fractographs of the crept specimens at $783 \mathrm{~K}\left(510^{\circ} \mathrm{C}\right)$ under different stresses with different magnifications.

[32]. Equiaxed dimpled fracture surfaces can be observed in micrographs at high magnification, and with the drop of the applied stress, i.e., with the increase in creep time, large dimples emerge and thus, the dimples' average size increases. Creep cavities are found to be surrounded by the ductile dimples, and a large amount of the observed dimples are centered around near-spherical particles. In general, the nucleation of microvoids preferentially takes place at precipitates or inclusions, acting as a stress concentrator; then, the voids grow together to form a macroscopic flaw, resulting 


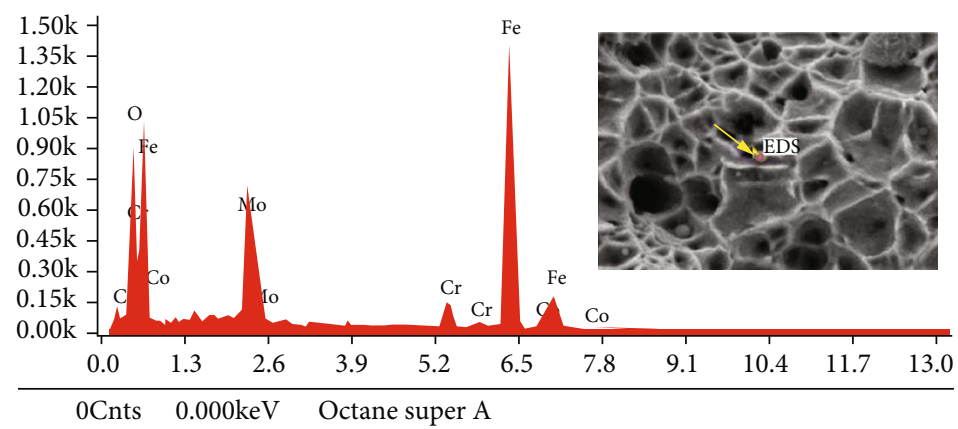

(a)

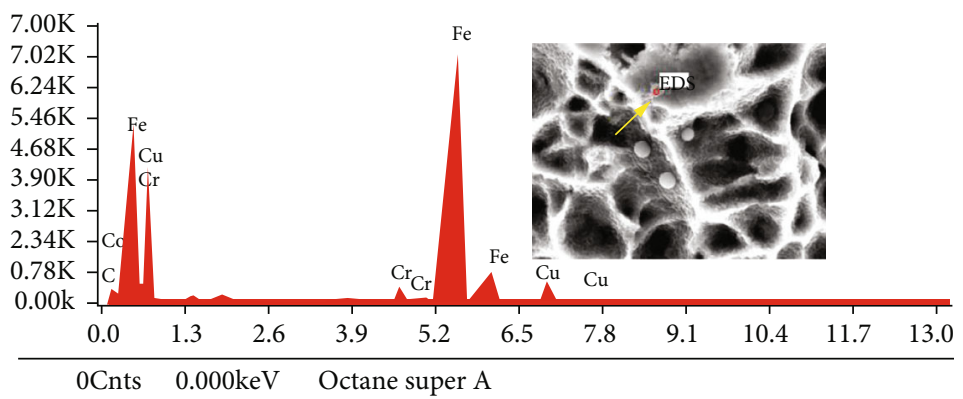

(b)

FIGURE 12: EDS spectrum of precipitates in the vicinity of the fracture surface in the specimen after 7386.5-hour creep testing.

into fracture. Herein, the fracture mechanism is the microvoid coalescence fracture, and the precipitates will create a stress concentration that can cause transgranular fracture initiation.

EDS analysis of the precipitates in Figure 12 shows that the precipitate contains metal elements like $\mathrm{Fe}, \mathrm{Cr}$, and Mo. According to previous studies $[12,33,34]$, the precipitates can be recognized as the Laves phase precipitates, which is an intermetallic phase of $\mathrm{W}$ and Mo recognized as $(\mathrm{Fe}, \mathrm{Cr})_{2}(\mathrm{~W}, \mathrm{Mo})$. And $\mathrm{W}$ is not obvious in the above precipitate since no $\mathrm{W}$ is added into $30 \mathrm{Cr} 1 \mathrm{Mo} 1 \mathrm{~V}$ and only $0.01 \mathrm{wt} . \% \mathrm{~W}$ is added to the FB2. About the formation mechanism of the Laves phase, some researchers believe that it swallows the $\mathrm{M}_{23} \mathrm{C}_{6}$ carbides by nucleating and growing on it and forms a cluster around prior grain boundaries [35]. After long-term creep, with the nucleation and growth of the Laves phase, the Mo and $\mathrm{W}$ contents are decreased; meanwhile, the pinning effect of the $\mathrm{M}_{23} \mathrm{C}_{6}$ is weakened, leading into the decrease in solid solution strengthening and creep strength, which will limit the life of component under high-temperature service condition; in addition, it is known that Laves precipitation can enhance the creep resistance by inhibiting the subgrain structure recovery and providing the pining effect to boundaries for short time creep, and such positive effect declines with creep time due to high coarsening rate [36]. Big-size Laves precipitates can act as cavity trigger, and precipitates larger than $130 \mathrm{~nm}$ changed the fracture mode from ductile to brittle according to the research of Panait et al. [37]. Besides the Laves phase, copper-rich precipitates containing $\mathrm{Fe}, \mathrm{Cu}, \mathrm{Cr}$, and $\mathrm{C}$ can be observed in the vicinity of the fracture surface. Xiao et al. [38] discussed solute-dislocation interactions and creep-enhanced $\mathrm{Cu}$-rich precipitate (CRPs) evolution in a novel ferritic-martensitic steel G115 during creep. And the large precipitates may nucleate microvoids which results into final fracture.

\section{Conclusions}

Dissimilar weldments between FB2 and 30Cr1Mo1V were obtained employing multipass submerged arc welding (SA-W) with backing weld being performed by tungsten inert gas arc welding (TIG-W). High-temperature creep tests at $783 \mathrm{~K}\left(510^{\circ} \mathrm{C}\right)$ were carried out for various applied stresses from 420 to $260 \mathrm{MPa}$. The creep rupture behavior of the dissimilar weldments are studied and summarized.

All creep samples fractured with a certain amount of localized plastic deformation in the weld fusion zone, which exhibits a heterogeneous microstructure as a result of multipass welding. The specimen does not break for the target time of $10,000 \mathrm{~h}$ under the lowest stress of $260 \mathrm{MPa}$, and the extrapolating strength of rupture time at $10,000 \mathrm{~h}$ with power law is $262 \mathrm{MPa}$, and the value predicted by LarsonMiller parameter is $259 \mathrm{MPa}$, which agree well with the experimental result. The base metal of FB2 exhibits greater microhardness values than $30 \mathrm{Cr} 1 \mathrm{Mo} 1 \mathrm{~V}$, whether before creep tests or after. The hardness in weld metal shows a decline trend with decreasing stress and increasing creep time, so the weld fusion zone changes from the maximum hardness region to the minimum as a result of creep, indicating that a softening phenomenon occurs in weld metal. The rupture occurs in the weld metal, probably as a result of the decreased dislocation density, the appearance of the 
microvoids, and precipitates during creep. The SEM morphologies at the smooth region of the ruptured specimens exhibit transgranular fracture features, and equiaxed dimpled fracture surfaces can be observed. With the increase in creep time, large dimples emerge and thus, the dimples' average size grows. Creep cavities are found to be surrounded by the ductile dimples, and a large amount of the observed dimples are centered around near-spherical particles. The particles are recognized as the Laves phase and $\mathrm{Cu}$-rich precipitates based on the EDS analysis. Microvoids preferentially nucleate at precipitates; then, the voids grow together to form a macroscopic flaw, which leads into eventual fracture.

\section{Data Availability}

The microstructure, hardness, and creep data used to support the findings of this study are included within the article.

\section{Conflicts of Interest}

The authors declare that there is no conflict of interest regarding the publication of this paper.

\section{Acknowledgments}

This research was supported by Industry-UniversityResearch Collaboration Project of Deyang, China (grant number 2018CKJ004).

\section{References}

[1] G. Cau, V. Tola, and P. Deiana, "Comparative performance assessment of USC and IGCC power plants integrated with $\mathrm{CO}_{2}$ capture systems," Fuel, vol. 116, pp. 820-833, 2014.

[2] Z. Ding, W. Yang, K. Huo, and L. Shaw, "Thermodynamics and kinetics tuning of $\mathrm{LiBH}_{4}$ for hydrogen storage," Progress in Chemistry, vol. 33, pp. 1586-1597, 2021.

[3] Z. Ding, S. Li, Y. Zhou et al., " $\mathrm{LiBH}_{4}$ for hydrogen storage New perspectives," Nano Materials Science, vol. 2, no. 2, pp. 109-119, 2020.

[4] F. N. Bayock, P. Kah, B. Mvola, and P. Layus, "Experimental review of thermal analysis of dissimilar welds of highstrength steel," Reviews on Advanced Materials Science, vol. 58, pp. 38-49, 2019.

[5] H. Chen, J. Huang, M. Ke, Z. Hua, and X. Zhao, "Influence of a $\mathrm{Ni}$-foil interlayer on $\mathrm{Fe} / \mathrm{Al}$ dissimilar joint by laser penetration welding," Materials Letters, vol. 79, pp. 296-299, 2012.

[6] C. R. Das, A. K. Bhaduri, G. Srinivasan, V. Shankar, and S. Mathew, "Selection of filler wire for and effect of auto tempering on the mechanical properties of dissimilar metal joint between 403 and 304L(N) stainless steels," Journal of Materials Processing Technology, vol. 209, no. 3, pp. 1428-1435, 2009.

[7] K. Laha, K. S. Chandravathi, K. Rao, S. L. Mannan, and D. H. Sastry, "An assessment of creep deformation and fracture behavior of 2.25Cr-1Mo similar and dissimilar weld joints," Metallurgical \& Materials Transactions A, vol. 32, no. 1, pp. 115-124, 2001.
[8] D. Jandová, J. Kasl, and V. Kanta, "Creep resistance of similar and dissimilar weld joints of P91 steel," High Temperature Technology, vol. 23, no. 3-4, pp. 165-170, 2006.

[9] J. Kasl, D. Jandová, S. T. Mandziej, and I. Schindler, Comparison of results of accelerated and conventional creep tests of dissimilar weld joint of steels FB2 and F, Trans Tech Publications, 2017.

[10] K. Laha, S. Latha, S. Bhanu, S. L. Mannan, and D. H. Sastry, "Comparison of creep behaviour of $2.25 \mathrm{Cr}-1 \mathrm{Mo} / 9 \mathrm{Cr}-1 \mathrm{Mo}$ dissimilar weld joint with its base and weld metals," Materials ence \& Technology, vol. 17, no. 10, pp. 1265-1272, 2013.

[11] I. J. Chilton, A. T. Price, and B. Wilshire, "Creep deformation and local strain distributions in dissimilar metal vvelds betvveen AISI type 316 and $2.25 \mathrm{Cr}-1 \mathrm{Mo}$ steels made vvith $17 \mathrm{Cr}-$ 8Ni-2Mo weld metal," Metal Science Journal, vol. 11, no. 1, pp. 383-391, 1984.

[12] J. Dagmar, "Quantitative evaluation of secondary phases in a weld joint made of COST F and FB2 creep resistant steels," Solid State Phenomena, vol. 270, pp. 183-188, 2017.

[13] V. Widak, B. Dafferner, S. Heger, and M. Rieth, "Investigations of dissimilar welds of the high temperature steels P91 and PM2000," Fusion Engineering and Design, vol. 88, no. 9-10, pp. 2539-2542, 2013.

[14] Z. Ding, P. Wu, and L. Shaw, "Solid-state hydrogen desorption of $2 \mathrm{MgH}_{2} \backslash+\mathrm{LiBH}_{4}$ nano-mixture: A kinetics mechanism study," Journal of Alloys and Compounds, vol. 806, pp. 350360, 2019.

[15] Z. Ding, Y. Lu, L. Li, and L. Shaw, "High reversible capacity

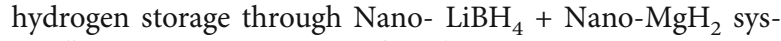
tem," Energy Storage Materials, vol. 20, pp. 24-35, 2019.

[16] V.Sklenička, K. Kuchařová, M. Svoboda, L. Kloc, J. Buršík, and A. Kroupa, "Long-term creep behavior of $9-12 \% \mathrm{Cr}$ power plant steels," Materials Characterization, vol. 51, no. 1, pp. 35-48, 2003.

[17] T. U. Kern, M. Staubli, and B. Scarlin, "The European efforts in material development for 650.DEG.C. USC power Plants. COST522," Transactions of the Iron \& Steel Institute of Japan, vol. 42, no. 12, pp. 1515-1519, 2002.

[18] M. Okazaki, M. Hashimoto, and T. Mochizuki, "Creep-fatigue strength of long-term post-service $2 \cdot 1 / 4 \mathrm{Cr}-1 \cdot$ Mo steel and remaining life estimation," Journal of Pressure Vessel Technology, vol. 113, no. 4, pp. 549-555, 1991.

[19] M. Nakashiro, S. Kihara, F. Kishimoto, and T. Fujimori, "Evaluation of long-term creep strength of $2.25 \mathrm{Cr}$ - 1 Mo heat transfer tube in actual service stress level range," ISIJ International, vol. 30, no. 10, pp. 823-828, 1990.

[20] T. Wada and V. Blšs, "Restoration of elevated temperature tensile strength in 2.25Cr-1Mo steel," Metallurgical Transactions A, vol. 14 , no. 4 , pp. 845-855, 1983.

[21] B. A. Senior, "A critical review of precipitation behaviour in $1 \mathrm{CrMoV}$ rotor steels," Materials Science \& Engineering A, vol. 103, no. 2, pp. 263-271, 1988.

[22] N. Shinya, J. Kyono, and H. Kushima, "Creep fracture mechanism map and creep damage of $\mathrm{Cr}-\mathrm{Mo}-\mathrm{V}$ turbine rotor steel," Transactions of the Iron \& Steel Institute of Japan, vol. 46, no. 10, pp. 1516-1522, 2006.

[23] R. L. Bodnar, T. Ohhashi, and R. I. Jaffee, "Errata: Effects of $\mathrm{Mn}, \mathrm{Si}$, and purity on the design of $3.5 \mathrm{NiCrMoV}, 1 \mathrm{CrMoV}$, and 2.25Cr-1Mo bainitic alloy steels," Metallurgical and Materials Transactions A, vol. 20, no. 10, pp. 2196-2212, 1989. 
[24] Y. Gong, J. Cao, L. Ji et al., “Assessment of creep rupture properties for dissimilar steels welded joints between T92 and HR3C," Fatigue \& Fracture of Engineering Materials \& Structures, vol. 34, no. 2, pp. 83-96, 2011.

[25] Y. Zhang, H. Jing, L. Xu et al., "Creep behavior and life assessment of a novel heat-resistant austenite steel and its weldment," Acta Metallurgica Sinica, vol. 32, pp. 638-650, 2019.

[26] D. Šeruga and M. Nagode, "Unification of the most commonly used time-temperature creep parameters," Materials Science \& Engineering A, vol. 528, no. 6, pp. 2804-2811, 2011.

[27] K. Maruyama, K. Sawada, and J. I. Koike, "Advances in Physical Metallurgy and Processing of Steels. Strengthening mechanisms of creep resistant tempered martensitic steel," ISIJ International, vol. 41, no. 6, pp. 641-653, 2001.

[28] X. Wang, K. Zhang, Z. Guo, N. Chen, Y. Rong, and H. Liu, “A new effect of retained austenite on ductility enhancement in high strength bainitic steel," Materials Science \& Engineering A, vol. 552, pp. 288-294, 2012.

[29] C. Pandey, M. M. Mahapatra, P. Kumar, and N. Saini, "Some studies on P91 steel and their weldments," Journal of Alloys and Compounds, vol. 743, pp. 332-364, 2018.

[30] S. K. Albert, M. Matsui, T. Watanabe, H. Hongo, and M. Tabuchi, "Variation in the type IV cracking behaviour of a high Cr steel weld with post weld heat treatment," International Journal of Pressure Vessels \& Piping, vol. 80, no. 6, pp. 405-413, 2003.

[31] J. Pešička, R. Kužel, A. Dronhofer, and G. Eggeler, “The evolution of dislocation density during heat treatment and creep of tempered martensite ferritic steels," Acta Materialia, vol. 51, no. 16, pp. 4847-4862, 2003.

[32] T. L. Anderson, Fracture Mechanics: Fundamentals and Applications, CRC Press, Taylor \& Francis Group, LLC, Fourth edition, 2017.

[33] H. G. Armaki, R. Chen, K. Maruyama, and M. Igarashi, "Creep behavior and degradation of subgrain structures pinned by nanoscale precipitates in strength-enhanced 5 to 12 Pct Cr ferritic steels," Metallurgical \& Materials Transactions A, vol. 42, no. 10, pp. 3084-3094, 2011.

[34] S. Yamasaki, M. Mitsuhara, K. I. Ikeda, S. Hata, and H. Nakashima, "Low-stress creep deformation in long-term aged ferritic heat-resistant steel," Materials Transactions, vol. 55, no. 5, pp. 842-849, 2014.

[35] G. Dimmler, P. Weinert, E. Kozeschnik, and H. Cerjak, "Quantification of the Laves phase in advanced 9-12\% Cr steels using a standard SEM," Materials Characterization, vol. 51, no. 5, pp. 341-352, 2003.

[36] K. Sawada, M. Takeda, K. Maruyama et al., "Effect of W on recovery of lath structure during creep of high chromium martensitic steels," Materials Science \& Engineering A, vol. 267, no. 1, pp. 19-25, 1999.

[37] C. G. Panait, W. Bendick, A. Fuchsmann, A. F. Gourgues-Lorenzon, and J. Besson, "Study of the microstructure of the Grade 91 steel after more than 100,000 h of creep exposure at $600{ }^{\circ} \mathrm{C}$," International Journal of Pressure Vessels \& Piping, vol. 87, no. 6, pp. 326-335, 2010.

[38] B. Xiao, L. Xu, C. Cayron, J. Xue, and R. Logé, “Solute-dislocation interactions and creep-enhanced $\mathrm{Cu}$ precipitation in a novel ferritic-martensitic steel," Acta Materialia, vol. 195, pp. 199-208, 2020. 